\title{
(6) OPEN ACCESS An immunohistochemical comparison of two TTF-1
monoclonal antibodies in atypical squamous lesions
and sarcomatoid carcinoma of the lung, and pleural
malignant mesothelioma*
}

\author{
Sonja Klebe, ${ }^{1,2}$ Adam Swalling, ${ }^{2}$ Lisa Jonavicius, ${ }^{2}$ Douglas W Henderson ${ }^{2}$
}

\begin{abstract}
${ }^{1}$ Department of Anatomical Pathology, Flinders University, Adelaide, South Australia, Australia

${ }^{2}$ Department of Surgical Pathology, SA Pathology at Flinders Medical Centre, Adelaide, South Australia, Australia
\end{abstract}

\section{Correspondence to}

Dr Sonja Klebe, Department of Anatomical Pathology, Flinders University, Bedford Park, Adelaide, SA 5042, Australia; Sonja.Klebe@health.sa.gov.au

*Presented in part at the 2015 Update Meeting of the Royal College of Pathologists of Australasia, Melbourne, Victoria (abstract published in Pathology 01/2015;47:S7677; doi:10.1097.

PAT.0000461535.76696.50).

Received 3 June 2015 Revised 17 July 2015 Accepted 26 July 2015 Published Online First 17 August 2015
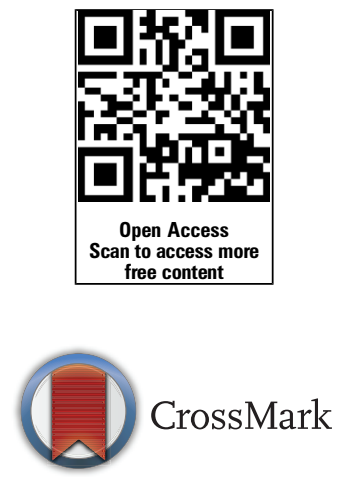

To cite: Klebe $S$, Swalling A, Jonavicius $L$, et al. J Clin Pathol 2016;69:136-141

\section{ABSTRACT}

Immunohistochemical detection of thyroid transcription factor-1 (TTF-1) plays an important role in the diagnosis and subclassification of non-small cell carcinomas of the lung in biopsy and some cytology samples, specifically for identification of squamous cell carcinoma (classically negative) and non-mucinous adenocarcinoma (positive in most cases) and for discrimination between lung adenocarcinoma and pleural malignant mesothelioma (classically negative).

Aims and methods We carried out a comparison of the widely used mouse monoclonal TTF-1 antibody based on the $8 \mathrm{G} 7 \mathrm{G} 3 / 1$ clone versus the more recently introduced rabbit monoclonal antibody (MAb) based on the SP141 clone.

Results Both antibodies labelled alveolar epithelium in normal lung parenchyma, but the SP141 antibody also labelled bronchial mucosal basal cells. All 13 cases of atypical squamous lesions (including one case of bronchial squamous dysplasia) were negative with the $8 \mathrm{G} 7 \mathrm{G} 3 / 1$ antibody, but $6 / 13$ cases of squamous carcinoma/dysplasia showed positive nuclear labelling with the SP141 antibody in the same tissue biopsy. All 35 cases of adenocarcinoma of the lung were positive with both antibodies. For 12 cases of sarcomatoid carcinoma of the lung, two cases were labelled with the $8 \mathrm{G} 7 \mathrm{G} 3 / 1$ antibody, whereas positive labelling of $4 / 12$ cases was observed with SP141. All 66 cases of epithelioid malignant mesothelioma were negative with both antibodies, but 8/19 cases of sarcomatoid mesothelioma showed positive nuclear labelling with the SP141 antibody (0/19 with 8G7G3/1).

Conclusions Our findings indicate differences in the rates of positive and negative labelling with these two antibodies, and suggest the potential for

misclassification of a proportion of squamous carcinomas of the lung as adenocarcinoma, and for misdiagnosis of some sarcomatoid mesotheliomas as sarcomatoid carcinoma of the lung. If the results of SP141 are assigned overriding significance, our findings further indicate that in isolation, neither negative labelling with either $8 \mathrm{G} 7 \mathrm{G} 3 / 1$ or SP141 nor positive labelling with the SP141 MAb discriminates between sarcomatoid carcinoma and sarcomatoid mesothelioma, whereas positive labelling with the $8 \mathrm{G} 7 \mathrm{G} 3 / 1 \mathrm{MAb}$ favours a diagnosis of sarcomatoid carcinoma. The literature suggests that these seemingly 'aberrant' results with the SP141 antibody are not 'false' positives, but rather real detection of low levels of TTF-1 protein in a broader range of tumours than is widely recognised.

\section{INTRODUCTION}

Immunohistochemical (IHC) studies for thyroid transcription factor-1 (TTF-1) have a wellestablished role in the pathological diagnosis of primary adenocarcinomas of the lung-with nuclear labelling of $60 \%-100 \%$ non-mucinous adenocarcinomas and less frequent labelling of mucinous adenocarcinomas ${ }^{1}{ }^{2}$-as well as follicular epithelial tumours of the thyroid gland. ${ }^{1}$ In this context, positive versus negative labelling for TTF-1 is of value for differential diagnosis in several situations, including both biopsy tissue and cytology preparations: (a) the investigation of poorly differentiated non-small cell carcinomas of the lung to facilitate discrimination between adenocarcinoma and squamous cell carcinoma (SCC); (b) to provide evidence that an adenocarcinoma in a bronchopulmonary biopsy represents metastatic carcinoma from an extrapulmonary site (negative labelling) and, conversely, that a carcinoma in an extrapulmonary site represents secondary adenocarcinoma from the lung (positive labelling) and (c) as a discriminator between adenocarcinoma versus pleural malignant mesothelioma. In the last of these situations, it has been claimed that mesotheliomas do not express TTF- $1,{ }^{3}$ and from pooled data in seven studies that investigated 355 epithelioid and 23 sarcomatoid mesotheliomas-all of which used the TTF-1 monoclonal antibody (MAb) based on the $8 \mathrm{G} 7 \mathrm{G} 3 / 1$ clone-Ordóñez ${ }^{1}$ found that none of the 378 cases showed evidence of TTF-1 expression.

Multiple different TTF-1 antibodies have been available commercially, including rabbit and goat polyclonal antibodies ${ }^{1}$ as well as mouse MAbs (8G7G3/1 and SPT24 clones) and, more recently, a rabbit MAb (SP141). There is evidence that the SPT24 MAb labels a broader range of neoplasms than the 8 G7G3/1-based TTF-1 MAb. ${ }^{1} 45$

The aim of this study was to compare the labelling profiles of two commercially available TTF-1 MAbs-the 8G7G3/1 (Dako) and SP141 (Ventana) TTF-1 MAbs-in primary adenocarcinoma of the lung, primary SCC and sarcomatoid carcinomas of the lung, and malignant mesothelioma. Our study was stimulated serendipitously in part by referral to two of us (DWH and SK) of one biopsy case where a preliminary diagnosis of pleural malignant mesothelioma had been suggested; our IHC investigations included a negative 8G7G3/1 TTF-1 result, with a favoured diagnosis of pleural sarcomatoid mesothelioma; the case was also evaluated by 
another laboratory where the SP141 MAb was used, with strong labelling of nuclei, and, therefore, an alterative diagnosis of sarcomatoid carcinoma was advanced; the same case was then investigated by a third laboratory with the SP141 MAb, with confirmation of obviously positive labelling of the tumour cell nuclei.

\section{MATERIALS AND METHODS}

A search of SA Pathology files at the Flinders Medical Centre (FMC) for the period from May 2014 to May 2015-comprising professional and medicolegal referrals and 'in-house' biopsy cases-yielded 85 malignant mesotheliomas (66 epithelioid, 19 sarcomatoid), 12 bronchial biopsy specimens of poorly differentiated SCC and one case of bronchial dysplasia, and 35 bronchial biopsies of primary lung adenocarcinomas, with tissue suitable and sufficient for additional IHC studies (ie, unstained slides and/or paraffin-embedded biopsy tissue). Only two cases of sarcomatoid carcinoma of the lung-defined as a poorly differentiated non-small cell carcinoma or adenocarcinoma with $>10 \%$ of spindle-cell sarcomatoid tissue with or without giant cells $^{6-9}$ - were accessioned during the same period. Therefore, we extended our search of the FMC archives backwards to 1992, with retrieval of 12 cases in all: those cases included six lung resections, two bronchial biopsies, two core biopsies of an intrapulmonary mass lesion and two represented pleural biopsies. The sarcomatoid spindle-cell tissue in one of the pleural biopsies had shown positive labelling for/with $5 / 6$ carcinoma-related markers; the other case was a parietal pleural biopsy from a patient who had undergone lung resection for a non-small cell carcinoma of the lung with invasion of the visceral pleura that corresponded to the site of the subsequent pleural biopsy. Cytology-only cases were excluded, as was any case for which no or insufficient material was available for additional IHC labelling for TTF-1 protein with both the $8 \mathrm{G} 7 \mathrm{G} 3 / 1$ and SP141 MAbs on sections from the same tissue block, including referral cases for which stained slides only were received, and in-house cases for which insufficient tissue remained after other ancillary studies such as molecular analysis for epidermal growth factor receptor mutation status. Nineteen cases of sarcomatoid mesothelioma that fulfilled the criteria for inclusion were accessioned during the 1-year period 20142015, and are included in this study. All of the mesothelioma diagnoses were considered definite on the basis of: (a) adequate biopsy tissue with IHC studies that included cytokeratin preparations, at least two and up to six mesothelial markers (cytokeratin 5/6, calretinin, WT1, D2-40, HBME-1 and thrombomodulin), multiple generic and more site-specific carcinoma-related markers (CEA, CD15, BG8, B72.3, TTF-1, \pm Ber-EP4, \pm other markers such as desmin and smooth muscle actin, CD31, CD34 and Stat6 in selected cases) ${ }^{10}$ and (b) clinical and radiological correlation to ensure that the anatomical localisation and distribution of the tumour were in no way discordant for a diagnosis of malignant mesothelioma. ${ }^{10}$ The cases were labelled in parallel with the Dako 8G7G3/1 and Ventana SP141 TTF-1 MAbs. Sections were stained using the Ventana BenchMark ULTRA immunohistochemistry slide staining system. The staining protocol for the SP141 used a $36 \mathrm{~min}$ antigen retrieval in Ventana Cell Conditioning 1 solution, and the protocol for the $8 \mathrm{G} 7 \mathrm{G} 3 / 1$ retrieval in Ventana Cell Conditioning 1 solution was for $32 \mathrm{~min}$. The antibodies were incubated for $32 \mathrm{~min}$ at $36^{\circ} \mathrm{C}$, with the $8 \mathrm{G} 7 \mathrm{G} 3 / 1$ being diluted 1:100, whereas the SP141 was prediluted. For the $8 \mathrm{G} 7 \mathrm{G} 3 / 1$, Ventana amplifier was used to increase the intensity of the staining. A Ventana ultraView Universal DAB Detection Kit was used followed by Ventana Hematoxylin as a nuclear counterstain.

\section{RESULTS}

\section{Primary lung adenocarcinoma}

All 35 cases of adenocarcinoma showed positive labelling with both TTF-1 MAbs.

\section{Bronchial squamous dysplasia and SCC}

Our results are shown in table 1 . Seven of the 13 cases contained non-neoplastic parenchymal lung tissue, which labelled strongly with both TTF-1 MAbs, serving as an internal quality control. In six cases, there was positive labelling of dysplastic/ malignant squamous epithelium for TTF-1 with the SP141 $\mathrm{MAb}$ (figures 1 and 2; table 1), whereas all of the cases were negative with the 8G7G3 MAb. We also observed labelling of the nuclei of bronchial mucosal basal cells with the SP141 MAb.

\section{Sarcomatoid carcinoma of the lung}

Two of the 12 cases showed positive labelling of nuclei with the 8G7G3/1 MAb, whereas 4/12 cases labelled with the SP141 $\mathrm{MAb}$ (table 1, where these results relate only to labelling of sarcomatoid tissue). The labelling of the spindle-cell sarcomatoid tissue, with or without tumour giant cells, varied from focal (but $>10 \%$ of the spindle-cell population) to extensive labelling with either MAb. In the lung resection specimens, there was consistent labelling of bronchial mucosal basal cells and, in some cases, labelling of mucosal columnar cells in addition.

\section{Malignant mesothelioma}

All 66 epithelioid mesotheliomas were TTF-1 negative with either antibody (table 1). Eight of the 19 sarcomatoid mesotheliomas showed labelling with the SP141 MAb (figure 3), including weak to focally moderate nuclear labelling of one desmoplastic mesothelioma (figure 4), but all 19 were negative with the 8G7G3/1 MAb (figure 5).

Table 1 Comparison of 8G7G3/1 and SP141 TTF-1 MAbs

\begin{tabular}{|c|c|c|}
\hline Tissue & $\begin{array}{l}\text { 8G7G3/1 } \\
\text { MAb: } n(\%)\end{array}$ & $\begin{array}{l}\text { SP141 MAb: } \\
\text { n (\%) }\end{array}$ \\
\hline Normal lung—alveolar epithelium & $7 / 7$ & $7 / 7$ \\
\hline Adenocarcinoma of the lung & $35 / 35$ & $35 / 35$ \\
\hline $\begin{array}{l}\text { Atypical squamous lesions-12 SCCs+1 } \\
\text { case of bronchial squamous dysplasia }\end{array}$ & $0 / 13$ & $5+1 / 12+1(\sim 46 \%)$ \\
\hline $\begin{array}{l}\text { Pleomorphic/sarcomatoid carcinoma of } \\
\text { the lung (spindle-cell component only) }\end{array}$ & $2 / 12(17 \%)$ & $4 / 12(\sim 33 \%)$ \\
\hline Epithelioid malignant mesothelioma & $0 / 66$ & $0 / 66$ \\
\hline Sarcomatoid mesothelioma & 0/19 & $8 / 19(\sim 42 \%)$ \\
\hline
\end{tabular}

We are unaware of any systematic data on the actual levels of TTF-1 expression in, for example, sarcomatoid carcinomas of the lung and sarcomatoid mesotheliomas, for estimation of the rates of true/false positive/negative IHC labelling of these tumours. Existing evidence indicates that positive IHC labelling for TTF-1 protein may not represent 'false'-positive labelling, but rather 'true' labelling in these cancers (ie, detectable labelling represents high affinity of the SP141 MAb in particular for low levels of TTF-1 protein in different cancers, with loss of diagnostic specificity for tumour classification by IHC). Ideally, these assessments should be made in comparison with true zero/augmented levels of mRNA as the template for TTF-1 protein-and as such the 'gold standard' test-but to the best of our knowledge systematic data on mRNA levels in these sarcomatoid tumours are unavailable (see text).

IHC, immunohistochemical; MAb, monoclonal antibody; SCC, squamous cell carcinoma; TTF-1, thyroid transcription factor-1. 


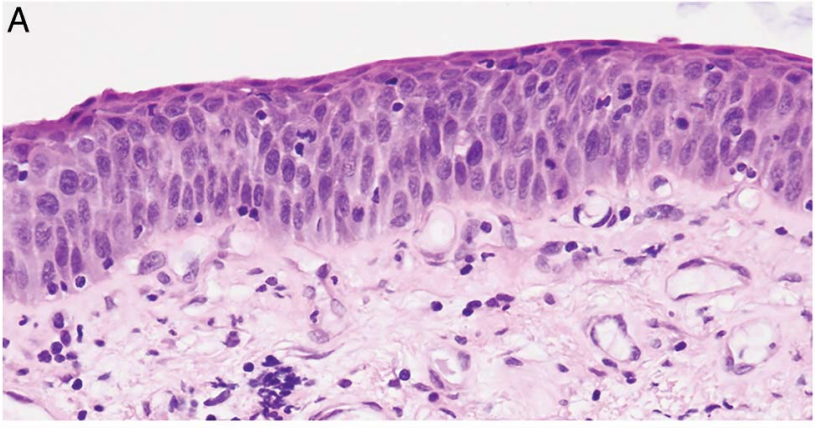

B

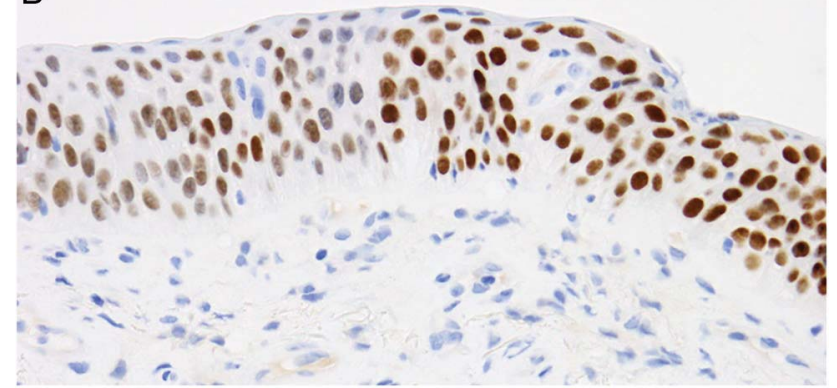

Figure 1 H\&E staining (top) and SP141 TTF-1 labelling (bottom) of dysplastic squamous bronchial epithelium. TTF-1, thyroid transcription factor-1.

\section{DISCUSSION}

TTF-1 is a homeodomain-containing nuclear factor that plays a crucial role in the development of the thyroid and lung, and in the normal development of the ventral brain and pituitary gland. ${ }^{1}$ Within the lung, TTF-1 stimulates the synthesis of lungspecific surfactant proteins, ${ }^{11-14}$ as well as Clara cell secretory protein. ${ }^{1}$ In mice, genetic ablation of the NKX2 gene on chromosome $14 \mathrm{q} 13$-which encodes TTF-1 protein ${ }^{1}{ }^{15}$-results in agenesis of the thyroid gland and lung hypoplasia, as well as forebrain defects. ${ }^{1}{ }^{16}$ TTF-1 protein is a polypeptide of 371 amino acids, ${ }^{1}$ and can be detected by immunohistochemistry in fetal lung epithelial cell nuclei by about 11 weeks of gestation. ${ }^{17} \mathrm{IHC}$ demonstration of TTF-1 protein is also useful for the identification of some primary lung tumours, especially non-mucinous adenocarcinomas, for which it is considered to be a reliable marker, with labelling of $60 \%-100 \%$ of such cases. ${ }^{1-3} 18$

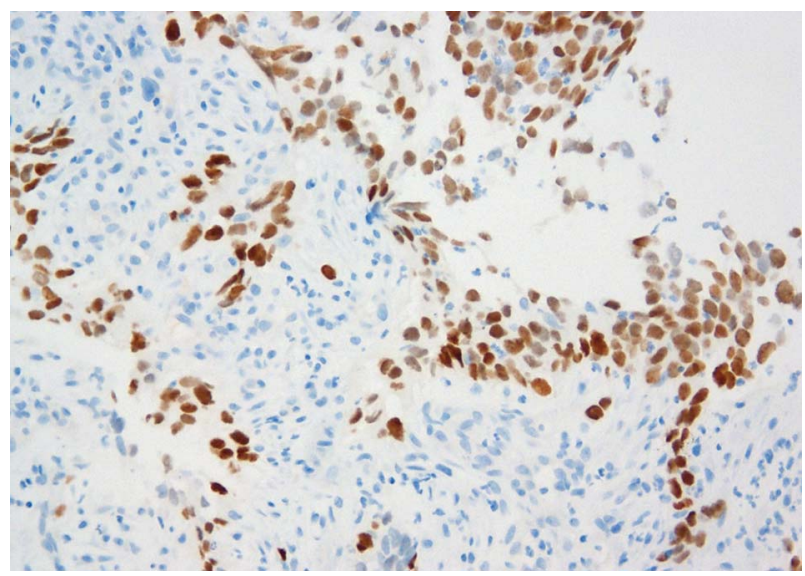

Figure 2 Squamous cell carcinoma showing labelling with the SP141 TTF-1 (bronchial biopsy). TTF-1, thyroid transcription factor-1.

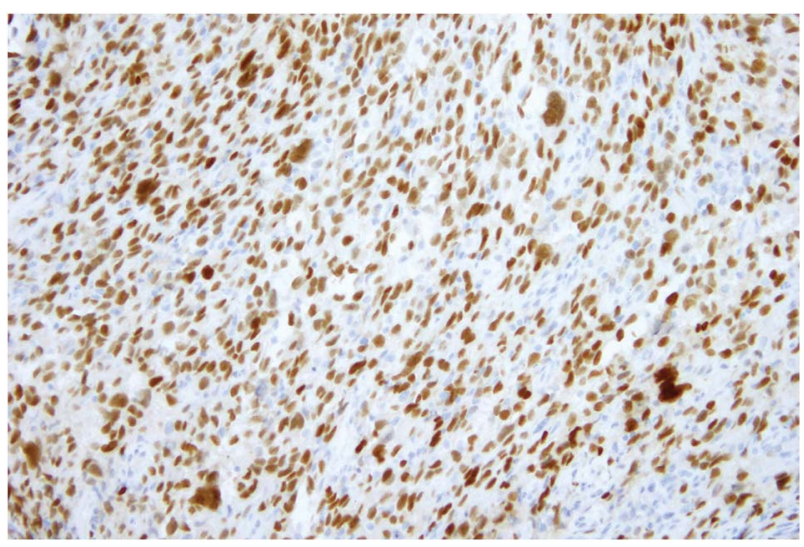

Figure 3 Sarcomatoid mesothelioma with positive nuclear labelling with the SP141 TTF-1 antibody. TTF-1, thyroid transcription factor-1.

The 8G7G3/1 MAb was the first TTF-1 MAb to become available commercially, ${ }^{15}$ and is the most widely used. ${ }^{1}{ }^{4}$ As shown in tables 1-9 in Ordóñez' 2012 review of multiple published studies on TTF-1 MAbs (as well as polyclonal antibodies), ${ }^{1}$ those studies that used the $8 \mathrm{G} 7 \mathrm{G} 3 / 1 \mathrm{MAb}$ greatly outnumbered those that used the SPT24 MAb: for example, his table 2 lists 2614 cases of adenocarcinoma of the lung across 37 references, in comparison with 579 cases in seven reports for SPT24, and the same table lists 17 studies for 428 cases of adenocarcinoma subtypes, whereas the table does not list any studies for the same adenocarcinoma subtypes using SPT24; His table 1 (thyroid tumours) lists 16 references where the 8G7G3/ $1 \mathrm{MAb}$ was used; no studies are listed for SPT24. In its 2014 Quality Assurance Program for immunohistochemistry, the Royal College of Pathologists of Australasia ${ }^{19}$ gave the SP141 TTF-1 MAb a higher score than the 8G7G3/1 MAb for TTF-1 expression because of the intensity and clarity of its labelling, but it was used by only $8 \%$ of the laboratories tested, and aberrant staining of plasma cells was noted; the $8 \mathrm{G} 7 \mathrm{G} 3 / 1$ clone was used by $56 \%$ of laboratories, but labelling was more commonly scored as borderline or unsatisfactory (the SPT24 MAb was ranked as intermediate between the SP141 and 8G7G3/1 MAbs,

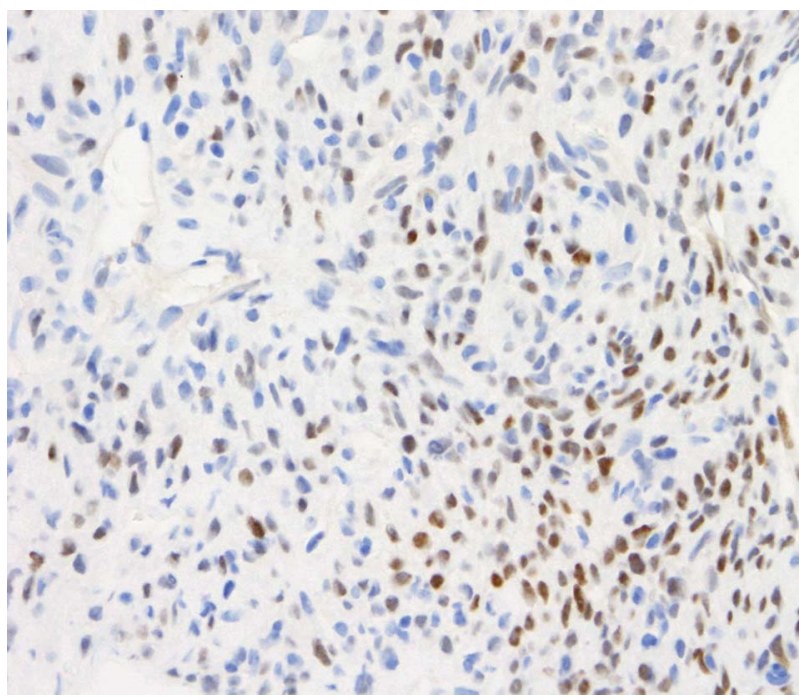

Figure 4 Core biopsy of pleura. Sarcomatoid mesothelioma with some desmoplastic features. Patchy weak-to-moderate labelling of tumour cell nuclei for TTF-1 with the SP141 antibody. 


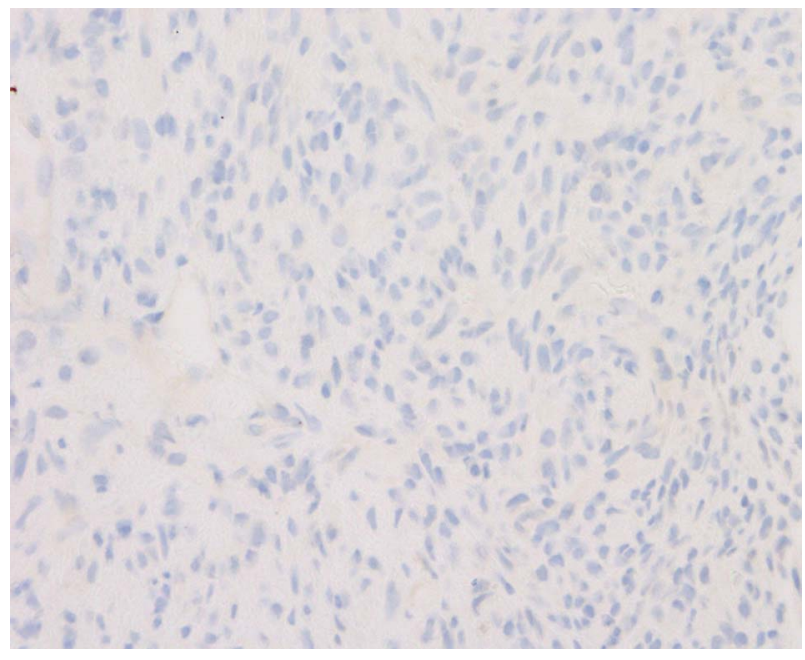

Figure 5 Sarcomatoid mesothelioma with some desmoplastic features, labelled with 8G7G3/1 TTF-1. Same case as figure 4. TTF-1, thyroid transcription factor-1.

and was used by $31 \%$ of the laboratories). An assessment performed by Nordic Quality Control found similar results with the SP141 clone, which was considered more sensitive than the $8 \mathrm{G} 7 \mathrm{G} 3 / 1 \mathrm{MAb}^{20}$ Matoso et $\mathrm{al}^{4}$ also depicted stronger labelling of lung adenocarcinomas with the SPT24 MAb with a higher detection rate for '... all histologic subtypes of non-small cell pulmonary primary tumors with a clear advantage over 8G7G3/ 1 in squamous cell carcinomas'.

It has become clear that labelling with TTF-1 MAbs is not restricted to adenocarcinomas of the lung and thyroid follicular epithelial neoplasms (and medullary carcinoma of thyroid), but it also occurs with small cell neuroendocrine (NE) carcinomas and non-small cell NE bronchopulmonary tumours and alsoalthough with lesser frequency-extrapulmonary NE carcinomas, as well as some sarcomatoid carcinomas of the lung. Across four series of sarcomatoid carcinoma cases for which the 8G7G3/1 MAb was used, Ordóñez ${ }^{1}$ listed 19/63 cases with positive labelling $(\sim 30 \%)$; in one of the four studies cited by Ordóñez, ${ }^{1} 43 \%$ of the pleomorphic carcinomas showed positive labelling, and $55 \%$ of the spindle-cell carcinomas were labelled positively. ${ }^{21}$ In contrast, Lucas et $a l^{22}$ found that all 10 cases of sarcomatoid carcinoma were negative with the 8G7G3/1 MAb, whereas Takeshima et $a l^{23}$ reported positive labelling of 3/20 cases $(15 \%)$ using the same MAb. With the SPT24 MAb, Terra et $a l^{9}$ recorded positive TTF-1 labelling in a higher proportion of pleomorphic/sarcomatoid carcinomas of the lung or a carcinoma comprising spindle and giant cells: they assessed only the sarcomatoid component and detected any degree of TTF- 1 positivity in 18/27 pleomorphic carcinomas (67\%), 1/5 pure spindle cell carcinomas and $3 / 3$ carcinosarcomas (this study also recorded labelling for/with 0-4 mesothelioma markers-calretinin, WT1, D2-40 and CK5/6-in some cases).

Labelling of variable proportions of other extrapulmonary neoplasms, including colonic adenocarcinomas, is also recorded -reviewed in detail by Ordóñez ${ }^{1}$ who recorded labelling of $11 /$ 594 cases of colonic adenocarcinoma (1.8\%) across multiple studies where the $8 \mathrm{G} 7 \mathrm{G} 3 / 1 \mathrm{MAb}$ was used versus $15 / 258$ cases in three studies where the SPT24 was used (5.8\%). Studies have also shown that the SPT24 MAb labels a wider spectrum of both pulmonary and extrapulmonary neoplasms-and with greater frequency - than the $8 \mathrm{G} 7 \mathrm{G} 3 / 1 \mathrm{MAb},{ }^{4} 520$ and includes, as but a few examples, thymomas, gliomas including glioblastomas, and carcinomas of the female reproductive tract.

In our study, all of the cases of normal lung showed positive labelling of alveolar epithelium with both the $8 \mathrm{G} 7 \mathrm{G} 3 / 1$ and SP141 MAbs, and all of the SCCs were negative with the 8G7G3/1 MAb; however, six of 13 cases of squamous lesions (12 SCCs and a single case of bronchial squamous dysplasia) showed positive labelling of nuclei with the SP141 MAb ( 46\%), and 4/12 sarcomatoid carcinomas of the lung also labelled with this $\mathrm{MAb}$, in comparison with 2/12 cases with 8G7G3/1. The SP141 MAb also labelled basal cells in normalappearing bronchial mucosa. Based on earlier studies using the 8G7G3/1 MAb, primary lung SCC has been regarded as usually TTF-1 negative, ${ }^{24} 25$ but in his survey of multiple studies, Ordóñez ${ }^{1}$ commented that across 23 reported series, TTF-1 positivity was recorded for 3\%-38\% of SCCs, whereas all cases in another 24 published series were negative (table 2 in Ordóñez's ${ }^{1}$ review records positive TTF-1 labelling of 42/1057 pulmonary SCCs (4\%) with the $8 \mathrm{G} 7 \mathrm{G} 3 / 1 \mathrm{MAb}$, in comparison with 23/142 cases with the SPT24 MAb ( 16\%) and 18.5\% with a polyclonal antibody). It was considered likely that the positive labelling in at least some cases was explicable by the presence of residual terminal airway epithelium entrapped by the carcinomas and misinterpreted as neoplastic cells. ${ }^{1}$ However, the product information package insert sheet for the SP141 MAb refers to $12 / 51$ SCCs of the lung with positive labelling for TTF-1 (23.5\%) in comparison with 3/38 cases for the package insert for the $8 \mathrm{G} 7 \mathrm{G} 3 / 1 \mathrm{MAb}$ produced by the same manufacturer $(\sim 8 \%))^{26}$ (Other potential factors that can potentially explain the differences reported across different publications include methodological issues such as antibody dilutions, antigen retrieval, detection systems and so forth. ${ }^{4}$ )

Current approaches to the differential diagnosis of poorly differentiated non-small cell carcinoma (for the distinction between SCC vs adenocarcinoma) in limited bronchopulmonary biopsy samples (or cytology specimens) include restricted use of antibodies for this assessment, to optimise the amount of tissue remaining for molecular studies (eg, for epidermal growth factor receptor (EGFR) receptor mutation or naplastic lymphoma kinase (ALK) mutation status). ${ }^{2}$ Travis $e t a l^{2}$ have commented that p63 is often positive in most nuclei of SCCs of the lung, but there may be patchy and/or weak staining in $20 \%$ $30 \%$ of adenocarcinomas (and that $\mathrm{p} 40$ is a superior marker for $\mathrm{SCC}^{2}$ ), but they also state that for a case '... positive for an adenocarcinoma marker such as TTF-1, the tumor should be classified as NSCLC, favor adenocarcinoma, despite any expression of squamous markers'; the same authors ${ }^{2}$ also comment that TTF-1 and p40 are '... generally mutually exclusive'. Our experience with the SP141 MAb suggests that this is probably not so for the SP141 TTF-1 MAb, with the potential for misclassification of some SCCs as adenocarcinoma. Accordingly and pending further investigation, we suggest that p63 may best be replaced by $\mathrm{p} 40$ and that for this specific situation, the more extensively investigated $8 \mathrm{G} 7 \mathrm{G} 3 / 1 \mathrm{MAb}$ may be preferable to the SP141 (or the SPT24) antibody, or the use of both of these MAbs for a particular case.

Based on findings with the $8 \mathrm{G} 7 \mathrm{G} 3 / 1$ clone MAb that only a small proportion of mesotheliomas show positive TTF-1 labelling, this antibody has been extensively used for distinction of mesothelioma from primary tumours intrinsic to the lung, ${ }^{1} 3$ and Hammar et $a l^{10}$ commented in 2008 that strong nuclear labelling for TTF-1 in a pleural epithelioid tumour represents strong evidence against a diagnosis of mesothelioma and favours an alternative diagnosis of adenocarcinoma of the lung. The 
results of our study further support this statement, but for epithelioid tumours only: all of the 66 epithelioid mesotheliomas were negative with each of the 8G7G3/1 and SP141 MAbs, and all 19 sarcomatoid mesotheliomas were negative with 8 G7G3/1, but $8 / 19$ sarcomatoid mesotheliomas $(\sim 42 \%)$ were positive with the SP141 MAb. Therefore, our study suggests that there is a significant potential for misclassification of a sarcomatoid mesothelioma as a sarcomatoid carcinoma of the lung when the SP141 MAb is used. Potential solutions to this problem would include continued use of the $8 \mathrm{G} 7 \mathrm{G} 3 / 1 \mathrm{MAb}$ or the use of 8 G7G3/1 in addition to SP141 for serosal sarcomatoid lesions, and to take into account the results for generic and other site-'specific' carcinoma-related markers. ${ }^{10}$ From our study, we conclude that neither negative nor positive labelling of a pleural sarcomatoid tumour with the SP141 MAb in isolation discriminates reliably between sarcomatoid carcinoma of the lung and pleural sarcomatoid mesothelioma, although positive nuclear labelling with the $8 \mathrm{G} 7 \mathrm{G} 3 / 1 \mathrm{MAb}$ represents evidence against a sarcomatoid mesothelioma and strongly favours the alternative diagnosis of sarcomatoid carcinoma.

We consider that the positive labelling of SCCs and sarcomatoid carcinoma of the lung and pleural sarcomatoid mesotheliomas with the SP141 MAb-and the more widespread labelling of various neoplasms with SPT24 as reported in the literaturemay reflect augmented sensitivity of those MAbs, with some resultant loss of specificity (table 1). Gene Expression Omnibus DataSets have shown mRNA expression for TTF-1 at low levels in some malignant pleural mesotheliomas, ${ }^{27}$ and Scorer et al

\section{Take home messages}

- Immunohistochemical studies for thyroid transcription factor-1 (TTF-1) protein play an important role for subclassification of non-small cell carcinomas in bronchopulmonary biopsies to facilitate distinction between primary non-mucinous adenocarcinoma (usually positive) and squamous cell carcinoma (usually negative) for the recognition of primary lung adenocarcinoma versus adenocarcinomas of non-pulmonary origin and for the discrimination between malignant mesothelioma (epithelioid and sarcomatoid) versus adenocarcinoma of the lung.

- Of the commercially available TTF-1 antibodies, the mouse monoclonal antibody based on the $8 \mathrm{G} 7 \mathrm{G} 3 / 1$ clone is the most widely used; mesotheliomas are characteristically negative with this MAb.

- In this series, the results with the two 8G7G3/1 and SP141 MAbs were concordant for all cases of adenocarcinoma (positive) and for all 66 cases of epithelioid malignant mesothelioma (negative).

- It appears that the SP141 MAb is more sensitive than $8 \mathrm{G} 7 \mathrm{G} 3 / 1$, with high affinity for detection of TTF-1 protein at the expense of tumour cell specificity.

- The different rates of positive and negative labelling with these two MAbs need to be taken into account to avoid misclassification of squamous carcinoma as adenocarcinoma, and sarcomatoid mesothelioma as sarcomatoid carcinoma of the lung.

- These differences also highlight the question of differential sensitivity/specificity for other antibodies used for diagnosis when multiple antibodies for each marker are available from different manufacturers. found that, for six cases of colonic adenocarcinoma positive with the SPT24 MAb, reverse transcriptase PCR (RT-PCR) demonstrated fragments of TTF-1 RNA transcripts indicative of TTF-1 gene expression and '... three smaller RNA fragments when sequenced provided evidence of a novel splice variant previously not described in the literature'.

Therefore, positive IHC labelling with the SP141 MAb-like the SPT24 MAb-may simply represent high sensitivity for very low levels of TTF-1 protein in a variety of tumours other than primary lung/thyroid adenocarcinomas and pulmonary (and extrapulmonary) small cell and non-small cell NE carcinomas, but it does carry implications for diagnosis and treatment. The differences between these two MAbs also highlight the question of the differential sensitivity/specificity for other antibodies used for diagnosis of other neoplasms, when multiple antibodies for each marker are available from different manufacturers. As stated by Bisceglia et $a l^{28}$ in relation to labelling of breast carcinoma with the SPT24 TTF-1 MAb: 'The Chosen Clone Matters'.

\section{Handling editor Cheok Soon Lee}

Contributors DWH and SK: idea, planning, scoring of immunohistochemical labelling, literature review and manuscript preparation. DWH: photography. AS: database search, scoring and manuscript review. LJ: immunohistochemical analysis, quality assurance for antibodies and optimisation, manuscript review.

Competing interests DWH and SK have prepared medicolegal reports for the courts in Australia, but they and the other authors declare no competing interests for this study.

Ethics approval Flinders Medical Centre/Flinders University approval 381/09 (diagnostic and prognostic factors for lung cancer and mesothelioma).

Provenance and peer review Not commissioned; externally peer reviewed.

Data sharing statement Any data can be shared with anyone who asks. Additional data include single cases of aberrant labelling, which we recorded, but did not include, for example, prostate cancer, colonic carcinoma. Formal and structured analysis of those is on way. We communicated our findings to Ventana who confirmed some of our findings independently.

Open Access This is an Open Access article distributed in accordance with the Creative Commons Attribution Non Commercial (CC BY-NC 4.0) license, which permits others to distribute, remix, adapt, build upon this work non-commercially, and license their derivative works on different terms, provided the original work is properly cited and the use is non-commercial. See: http://creativecommons.org/ licenses/by-nc/4.0/

\section{REFERENCES}

1 Ordóñez NG. Value of thyroid transcription factor-1 immunostaining in tumor diagnosis: a review and update. Appl Immunohistochem Mol Morphol 2012;20:429-44

2 Travis WD, Brambilla E, Noguchi M, et al. Diagnosis of lung cancer in small biopsies and cytology: implications of the 2011 International Association for the Study of Lung Cancer/American Thoracic Society/European Respiratory Society Classification. Arch Pathol Lab Med 2013;137:668-84.

3 Husain AN, Colby T, Ordonez N, et al. Guidelines for pathologic diagnosis of malignant mesothelioma: 2012 update of the consensus statement from the International Mesothelioma Interest Group. Arch Pathol Lab Med 2012;136:1-21.

4 Matoso A, Singh K, Jacob R, et al. Comparison of thyroid transcription factor-1 expression by 2 monoclonal antibodies in pulmonary and nonpulmonary primary tumors. Appl Immunohistochem Mol Morphol 2010;18:142-9.

5 Scorer PW, Pinkney M, McIntosh GG. Thyroid transcription factor-1 (TTF-1): protein expression is not exclusive to lung and thyroid tissue. Newcastle upon Tyne, UK: Leica Biosystems Newcastle Ltd. http://www.leicabiosystems.com [search Scorer].

6 Travis WD, Colby TV, Corrin B. Histological typing of lung and pleural tumours. 3rd edn. Berlin: Springer, 1999.

7 Travis WD, Brambilla E, Müller-Hermelink HK, et al., eds. Pathology and genetics of tumours of the lung, pleura, thymus and heart. Lyon: IARC, 2004.

8 Hasleton P. Sarcomatoid carcinoma, pleomorphic carcinoma, spindle cell carcinoma, giant cell carcinoma, carcinosarcoma, and pulmonary blastoma. In: Tomashefski JF Jr, ed. Dail and Hammar's pulmonary pathology. Vol. 2. 3rd edn. New York: Springer, 2008:375-97. 
9 Terra SB, Aubry MC, Yi ES, et al. Immunohistochemical study of 36 cases of pulmonary sarcomatoid carcinoma-sensitivity of TTF-1 is superior to napsin. Hum Pathol 2014;45:294-302.

10 Hammar SP, Henderson DW, Klebe S, et al. Neoplasms of the pleura. In: Tomashefski JF Jr, ed. Dail and Hammar's pulmonary pathology. Vol 2. 3rd edn. New York: Springer, 2008:558-734.

11 Bohinski RJ, Di Lauro R, Whitsett JA. The lung-specific surfactant protein B gene promoter is a target for thyroid transcription factor 1 and hepatocyte nuclear factor 3 , indicating common factors for organ-specific gene expression along the foregut axis. Mol Cell Biol 1994;14:5671-81.

12 Bruno MD, Bohinski RJ, Huelsman KM, et al. Lung cell-specific expression of the murine surfactant protein A (SP-A) gene is mediated by interactions between the SP-A promoter and thyroid transcription factor-1 [published erratum appears in J Biol Chem 1995 Jul 7;270(27):16482]. J Biol Chem 1995;270:6531-6.

13 Bejarano PA, Baughman RP, Biddinger PW, et al. Surfactant proteins and thyroid transcription factor-1 in pulmonary and breast carcinomas. Mod Pathol 1996;9:445-52.

14 Kelly SE, Bachurski CJ, Burhans MS, et al. Transcription of the lung-specific surfactant protein $\mathrm{C}$ gene is mediated by thyroid transcription factor 1. J Biol Chem 1996;271:6881-8.

15 Holzinger A, Dingle S, Bejarano PA, et al. Monoclonal antibody to thyroid transcription factor-1: production, characterization, and usefulness in tumor diagnosis. Hybridoma 1996;15:49-53.

16 Bingle CD. Thyroid transcription factor-1. Int J Biochem Cell Biol 1997;29:1471-3.

17 Stahlman MT, Gray ME, Whitsett JA. Expression of thyroid transcription factor-1 (TTF-1) in fetal and neonatal human lung. J Histochem Cytochem 1996;44:673-8.
18 Khoor A, Whitsett JA, Stahlman MT, et al. Utility of surfactant protein B precursor and thyroid transcription factor 1 in differentiating adenocarcinoma of the lung from malignant mesothelioma. Hum Pathol 1999;30:695-700.

19 RCPA Quality Assurance Program: Anatomical Pathology Immunohistochemistry Technical Module Generic Report, Survey IHT14-1. Issued 11/06/2014.

20 NordiQC. Thyroid transcription factor-1 (TTF-1): assessment run 392013 (earlier run 23 2008). 2013. http://www.nordiqc.org/

21 Rossi G, Cavazza A, Sturm N, et al. Pulmonary carcinomas with pleomorphic sarcomatoid, or sarcomatous elements: a clinicopathologic and immunohistochemical study of 75 cases. Am J Surg Pathol 2003;27:311-24.

22 Lucas DR, Pass HI, Madan SK, et al. Sarcomatoid mesothelioma and its histological mimics: a comparative immunohistochemical study. Histopathology 2003:42:270-9.

23 Takeshima Y, Amatya VJ, Kushitani K, et al. Value of immunohistochemistry in the differential diagnosis of pleural sarcomatoid mesothelioma from lung sarcomatoid carcinoma. Histopathology 2009;54:667-76.

24 Jerome Marson V, Mazieres J, Groussard 0, et al. Expression of TTF-1 and cytokeratins in primary and secondary epithelial lung tumours: correlation with histological type and grade. Histopathology 2004;45:125-34

25 Yang M, Nonaka D. A study of immunohistochemical differential expression in pulmonary and mammary carcinomas. Mod Pathol 2010;23:654-61.

26 Primary antibodies. http://www.ventana.com (accessed 25 May 2015)

27 GEO DataSets NXK2-1. ID10537470. http://www.ncbi.nlm.nih.gov/geo/tools/ profileGraph.cgi?ID=GDS1220:211024_s_at (accessed 26 May 2015).

28 Bisceglia M, Galliani C, Rosai J. TTF-1 expression in breast carcinoma-the chosen clone matters. Am J Surg Pathol 2011;35:1087-8. 